\title{
Observatório da Educação em Direitos Humanos (OBEDHUC) e a Formação de Professores no estado da Bahia aspectos institucionais, epistemológicos, metodológicos e éticos
}

"A Educação é a arma mais poderosa que você tem para transformar o mundo" Nelson Mandela

"A melhor forma de combater o fanatismo e o extremismo é defender os direitos humanos" Françoise Tukkens

“A formação de profissionais da educação em e para os direitos humanos não se dá apenas pela cognição, isto é, não se forma um educador apenas lendo livros e assistindo aulas. É preciso que este profissional vivencie a realidade das comunidades participando do dia a dia desses grupos e contribuindo na resolução de problemas concretos, pois é a emoção que abre as portas para o conhecimento humano e profissional."

José Cláudio Rocha

\section{RESUMO}

Este artigo relata a experiência do Observatório da Educação em Direitos Humanos (OBEDHUC) como a formação de profissionais da educação no estado da Bahia. Apresenta sua institucionalização como Laboratório de Pesquisa Aplicada em Ciências Humanas, Sociais e Sociais Aplicadas (CHSSA) vinculado ao Centro de Referência em Desenvolvimento e Humanidades (CRDH), órgão suplementar da Universidade do Estado da Bahia (UNEB), criado pela Resolução CONSU/UNEB 1247/2016. Descreve sua missão, visão e objetivos destacando os principais aspectos epistemológicos e metodológicos do processo de formação de profissionais da educação. Trata dos fundamentos da educação em e para os direitos humanos, das abordagens baseadas em direitos humanos, da indissociabilidade entre pesquisa, extensão e ensino, com foco em práticas educacionais inovadoras, entre outros temas. Por fim, apresenta os principais resultados obtidos pelo projeto e sua transição como laboratório de um Centro de Pesquisa.

\section{PALAVRAS-CHAVES}

Observatório da educação; educação em direitos humanos; metodologias participativas; abordagens baseadas em direitos humanos; Universidade do Estado da Bahia - UNEB. 


\title{
autêntica
}

\begin{abstract}
This article reports on the experience of the Observatory of Education in Human Rights as the teatchig of education professionals in the state of Bahia. Discusses its institutionalization as a research laboratory in education, social sciences and applied social sciences, in the Center of Reference in Development and Humanities (CRDH), Resolution CONSU/UNEB 1247/2016. Report its mission, vision, objectives and epistemological and methodological aspects of the process of training education Professional. It deals with the fundamentals of education in and for human rights, human rights based approaches, the inseparability of research, extension and teaching, focusing on innovative educational practices, among other topics. Finally, it presents the main results obtained by the project and its transition as laboratory of a Research Center.
\end{abstract}

\section{KEYWORDS}

Observatory of education; Human Rights Education; Participatory Methodologies; Approaches Based on Human Rights; University of the State of Bahia - UNEB. 


\section{autêntica}

\section{INTRODUÇÃO}

O relato de experiências é uma forma contemporânea de produção e difusão do conhecimento ao permitir que os atores possam, a partir de suas vivências concretas, refletir sobre os diversos aspectos da ação elaborando e reelaborando o conhecimento para a sua socialização. Consideramos também importante esse tipo de reflexão por propiciar que o conhecimento tácito (fruto da experiência e vivência das pessoas) possa ser convertido em conhecimento expresso, materializado em livros, capítulos de livros e artigos científicos como este que apresentamos aqui. Acreditamos ser possível aprender com essas experiências e reelaborar as ideias a partir de suas próprias experiências, diversidade e objetivos desejados.

O presente texto, portanto, relata a experiência do Observatório da Educação em Direitos Humanos (OBEDHUC) no estado da Bahia, no período de 2013 a 2016, destacando as ações voltadas para a formação de profissionais da educação (professores e gestores) da rede de educação básica e da universidade. O foco dessa ação foi proporcionar aos profissionais da educação um ambiente e atividades de formação e pesquisa em educação em direitos humanos favorecendo a emancipação das pessoas e grupos envolvidos, o empoderamento das comunidades, a luta contra a cultura da exclusão e da opressão social, bem como a libertação de todas as pessoas e a luta contra todas as formas de preconceito.

O recorte do OBEDHUC é o trabalho com as temáticas: Educação em Direitos Humanos (EDH); Educação para a Diversidade (ED); Educação Ambiental (EA); Educação para as Relações Étnico-Raciais (ERC) e Educação Planetária e Global (EPG), proposta por documentos internacionais como a Declaração Universal dos Direitos Humanos e nacionais como o Plano Nacional de Educação (PNE), Plano Nacional de Educação em Direitos Humanos (PNEDH), Programa Nacional de Direitos Humanos (PNDH), Diretrizes Nacionais Curriculares da Educação em Direitos Humanos, Resolução n. 01 do Conselho Nacional de Educação (CNE). Trabalha ainda com o Plano Nacional de Pós-Graduação (PNPG) 2011 a 2020 no que diz respeito a redução das assimetrias intra e inter-regionais e articulação da pós-graduação stricto sensu com a educação básica.

Discute o artigo a missão, visão e objetivos do OBEDHUC especialmente em relação à formação de profissionais da educação par as temáticas listadas acima, estimulando a que estes profissionais integrem esse conhecimento aos planos e projetos de suas respectivas instituições de ensino. Discute os aspectos epistemológicos, metodológicos e éticos da formação de profissionais em e para os direitos humanos, destacando os princípios que balizam a ação como um todo.

Por fim, o artigo conclui apresentando os aspectos principais da discussão e projetos para o futuro como aprofundamento dos seminários de metodologias participativas e oferta de cursos de graduação e pós-graduação lato e stricto sensu.

\section{ORIGEM E INSTITUCIONALIZAÇÃO DO OBSERVATÓRIO DA EDUCAÇÃO EM DIREITOS HUMANOS (OBEDHUC)}

O Observatório da Educação em Direitos Humanos (OBEDHUC)1 foi criado no ano de 2013 a partir da chamada pública 049/2012 da Coordenação de Aperfeiçoamento de Pessoal de Nível Superior (CAPES) em parceria com o Instituto Nacional de Estudos e Pesquisas Educacionais Anísio Teixeira (INEP) e a Secretaria

1 Originalmente o Observatório da Educação foi batizado com o nome Observatório da Educação, Direitos Humanos, Cidadania e Violência (OBEDHCV). Todavia, com o fim do projeto com a CAPES o nome foi alterado para OBEDHUC. 


\section{autêntica}

de Educação Continuada, Alfabetização, Diversidade e Inclusão (SECADI), dentro do Programa Observatório da Educação (OBEDUC), instituído pelo Decreto Presidencial 5.803 de 08 de junho de 2006, com o objetivo de fomentar estudos e pesquisas em educação, que utilizem a infraestrutura disponível das instituições de ensino superior (IES) e as bases de dados existentes no INEP. O Programa OBEDUC/CAPES visa, principalmente, proporcionar a articulação entre pós-graduação, licenciaturas e escolas de educação básica e estimular a produção acadêmica e a formação de recursos pós-graduados, em nível de mestrado e doutorado.

Com base no objetivo do Programa OBEDUC/CAPES e nas Diretrizes do Plano Nacional de Pós-Graduação (PNPG) 2011 a 2020, principalmente, em relação à cooperação da pós-graduação stricto sensu com a educação básica e a redução das assimetrias intra e inter-regionais, a missão do OBEDHUC é ser um ponto de convergência para a rede de pesquisa e formação de profissionais em educação em temas como: Educação em e para os Direitos Humanos (EDH); Educação para a Diversidade (ED); Educação para as relações étnico-raciais (ERC); Educação Ambiental (EA); Educação Planetária ou Global (EG)² entre outras.

Fomentar a produção e difusão de conhecimento, assim como formar recursos humanos de nível superior (doutorado, mestrado, iniciação científica e professores investigadores da rede de educação básica) constituem o objetivo primordial do OBEDHUC em nosso estado.

A visão de nosso Observatório da educação é ser referência em pesquisa, extensão e ensino, como foco na inovação, principalmente, em práticas inovadoras educacionais participativas e emancipatórias no Brasil e na América Latina. Por práticas educacionais participativas e emancipatórias entendemos práticas que favoreçam a cultura da paz, dos direitos humanos e da cidadania, que contribuam para o processo de emancipação individual e coletiva dos sujeitos envolvidos, que colaborem na superação da cultura da exclusão e na luta contra todas as formas de opressão, libertação dos seres humanos e na formação de um Estado promotor da cidadania e dos direitos humanos.

Para realização de sua missão-visão-objetivo o OBEDHUC foi institucionalizado - como base nos Estatutos e Regimento Geral da UNEB - como órgão de apoio acadêmico-administrativo. Do ponto de vista científico-acadêmico ele é um Laboratório de Pesquisa Aplicada em Ciências Humanas, Sociais e Sociais Aplicadas (CHSSA) vinculado ao Centro de Referência em Desenvolvimento e Humanidades (CRDH/UNEB) ${ }^{3}$.

Por seu turno, o CRDH/UNEB é um órgão suplementar da universidade com autonomia acadêmico-administrativa-financeira, área de atuação em todo o estado da Bahia, especialmente, no Território Metropolitano do Estado da Bahia, onde funcionam, além do OBEDHUC, mais 04 (quatro) laboratórios de pesquisa aplicada em Ciência Humanas, Sociais e Sociais Aplicadas ${ }^{4}$. Esse modelo de organização-institucionalização vem sendo considerado ideal pela universidade pois possibilita a continuidade do projeto dentro do Centro de Pesquisa.

2 A tese de doutoramento de Javier Ruano sobre Educação Planetária defendida no DMMDC e desenvolvida em cooperação com o OBEDHUC foi premiada no Equador pela Fundação Columbia, como melhor tese que relaciona ciência e espiritualidade e na Universidade de Salamanca como melhor tese de filosofia. O OBEDHUC intermediou a ida de Javier Ruano a Universidade de Salamanca no doutorado sanduiche e foi responsável por atestar os trabalhos realizados por este pesquisador no Brasil junto ao governo espanhol.

3 O Centro de Referência em Desenvolvimento e Humanidades (CRDH/UNEB) criado pela Resolução CONSU/UNEB 1247 de 16 de janeiro de 2016, com sede na Rua Gregório de Matos, n. 27, Pelourinho, Centro Histórico de Salvador, Bahia, mantém 05 (cinco) laboratórios de pesquisa multiusuários voltados à pesquisa em ciências humanas, sociais e sociais aplicadas.

4 Além do OBEDHUC, são laboratórios do CRDH/UNEB a Incubadora Tecnológica de Economia Solidária e Criativa - CRIAATIVA S³, o Portal Mbote (http://www.portalmbote,org), o Laboratório de Imagem, Memória e Documentação (LIMDO) e o Laboratório de Áudio, Sonorização e Iluminação (LASIO). O CRDH/UNEB é constituído como órgão suplementar da UNEB e reúne hoje mais de cinquenta pesquisadores voluntários. 


\section{autêntica}

Em seu processo de institucionalização o OBEDHUC está atrelado ao Grupo de Pesquisa Gestão, Educação e Direitos Humanos (GEDH/UNEB/CNPq) e a 03 (três) programas de pós-graduação stricto sensu: Mestrado Profissional em Gestão e Tecnologia aplicada à Educação (GESTEC); Mestrado Profissional em Propriedade Intelectual e Transferência de Tecnologia aplicada à Inovação (PROFNIT); Doutorado Multi-Institucional e Multidisciplinar em Difusão do Conhecimento (DMMDC). O OBEDHUC é considerado um laboratório de pesquisa por estes programas, essa relação com a pós-graduação acaba por atrair muitos jovens pesquisadores para o Observatório pela possibilidade de nele amadurecer seus projetos de investigação, antes de submeter a pós-graduação. Na figura 01, apresentamos a relação entre laboratório - grupo de pesquisa - centro de pesquisa.

\section{FIGURA O1 - RELAÇÃO ENTRE LABORATÓRIO, GRUPO DE PESQUISA E CENTRO} DE PESQUISA, EXTENSÃO E ENSINO

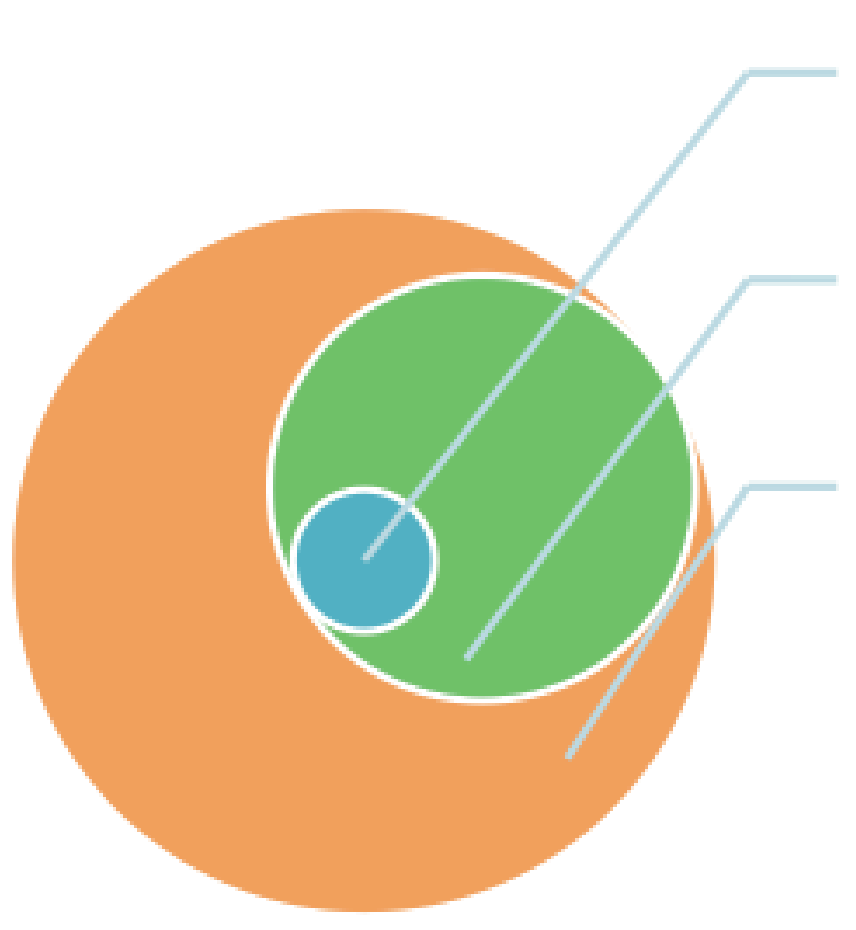

\author{
OBEDHUC \\ Laboratório de \\ pesquisa aplicada
}

\section{GEDH}

Grupo de pesquisa, Gestão e Dreitos

Humanos

CRDH

Centro de Referência

em Desenvolvimento

e Humanidades

Figura 1 - Elaboração CRDH/UNEB

Em relação à produção científica de 2013 a 2016 foram defendidas dentro do OBEDHUC: 04 (quatro) teses de doutorado; 11 (onze) dissertações de mestrado profissional; 06 (seis) projetos de iniciação científica; e 09 (nove) projetos de extensão universitária. Mais de uma centena de artigos e capítulos de livros foram publicados pelos participantes, sem contar inúmeras apresentações de trabalhos em congressos científicos, minicursos realizados, seminários e worshops voltados para a formação de professores. Todo esse acervo está organizado na biblioteca do CRDH/UNEB.

Essa produção só é possível porque o OBEDHUC se constitui num espaço de livre circulação de ideias, num ambiente onde é possível formar o ethos acadêmico, comportamento essencial na formação do pesquisador. 


\section{autêntica}

O OBEDHUC permite que o interessado possa aqui elaborar seu projeto de pesquisa até a apresentação a um programa de pós-graduação, assim como desenvolver pesquisa e projetos de investigação.

Utilizamos no OBEDHCU o método da colmeia, isto é, trabalhamos inicialmente com multiplicadores, pessoas proativas que já demonstram interesse nas temáticas elaboradas pelo Observatório. Em seguida, chegaremos aos ativos, profissionais da educação que sabem da importância das temáticas mais ainda não estão engajados na discussão e or final chegaremos aos reativos, grupo de pessoas que contestam essa discussão, A figura 2 apresenta o método da colmeia trabalhado pelo OBEDHUC.

\section{FIGURA -2 - MÉTODO DA COLMÉIA}

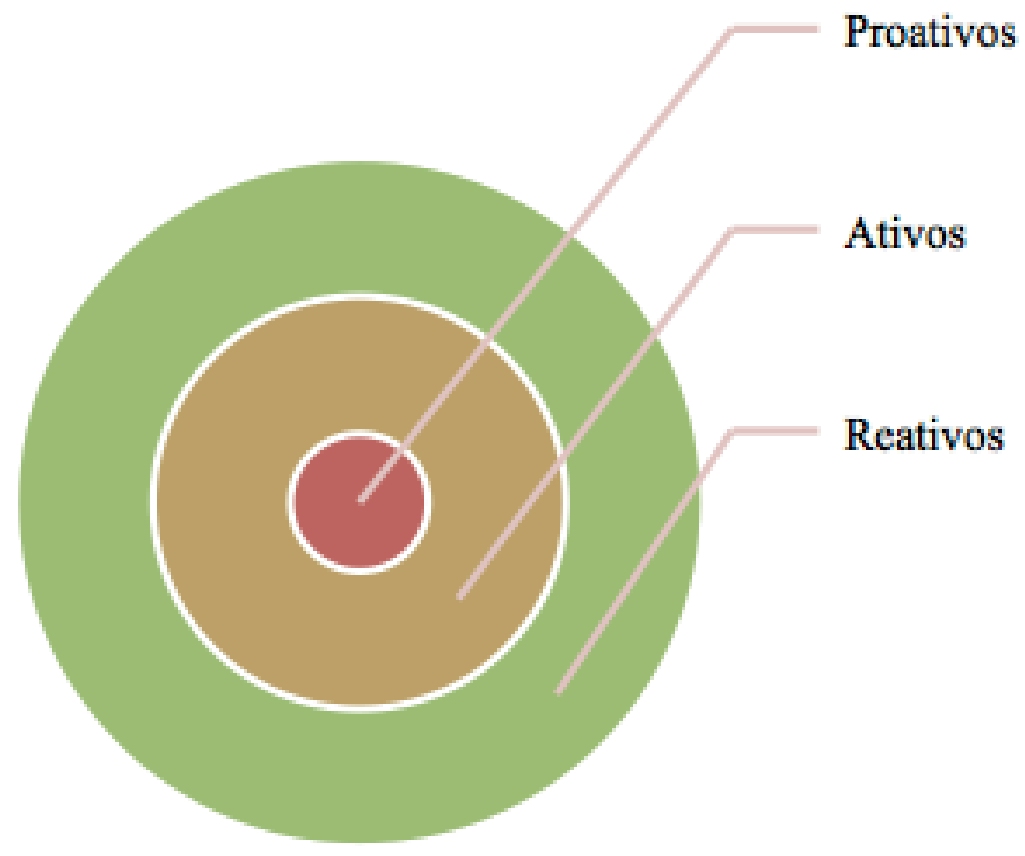

Figura 2 - Elaboração OBEDHUC

Com essa metodologia não dispersamos energia, concentrando nossos esforços e recursos na formação de uma massa crítica voltada para a construção de uma cultural de respeito e promoção dos direitos humanos. Essa mobilização social é fundamental para a efetivação das políticas públicas educacionais.

A base legal para atuação do OBEDHUC está na legislação nacional e universitária, especialmente na Constituição Federal de 1988, na Lei de Diretrizes e Bases da Educação Nacional (LDB), no Plano Nacional de Educação (PNE) 2014 a 2024, no Plano Nacional de Pós-Graduação (PNPG) 2011 a 2020, no Programa Nacional de Direitos Humanos (PNDH) terceira versão, no Plano Nacional de Educação em Direitos Humanos (PNEDH), nas Diretrizes Nacionais Curriculares para a Educação em Direitos Humanos, Resolução n 01/2012 do Conselho Nacional da Educação (CNE). No Estatuto e Regimento Geral da UNEB, resoluções e em seus próprios regulamentos. 


\section{autêntica}

\section{ASPECTOS EPISTEMOLÓGICOS E METODOLÓGICOS DA FORMAÇÃO DE PROFISSIONAIS DA EDUCAÇÃO}

\subsection{A FORMAÇÃO DE PROFISSIONAIS DA EDUCAÇÃO EM E PARA OS DIREITOS HUMANOS}

A formação em e para os direitos humanos de profissionais da educação é o recorte de nosso Observatório. Seu público interativo (alvo) pode ser encontrado no Plano Nacional de Educação em Direitos Humanos (PNEDH) e é formado pelos seguintes grupos: a) Professores da rede de educação básica; b) Professores e estudantes universitários; c) Profissionais de justiça e segurança; d) Profissionais do terceiro setor; e) Profissionais da mídia.

Vale a pena destacar que a educação é um direito humano indispensável a realização de outros direitos como trabalho, moradia, saneamento básico etc. Como tal a política pública que trata disso é o Plano Nacional de Educação (PNE) de 2014 a 2024. No entanto, a educação também é vista como meio, como a principal estratégia para a construção de uma cultura de respeito aos direitos humanos, nesse caso a política pública é o Programa Nacional de Direitos Humanos (PNDH), o Plano Nacional de Educação em Direitos Humanos (PNEDH) e as Diretrizes Nacionais Curriculares para a Educação em Direitos Humanos do Conselho Nacional de Educação (CNE).

Nesse sentido, a educação em direitos humanos é compreendida como um processo sistemático e multidimensional que orienta a formação dos sujeitos de direitos, articulando várias dimensões como a apreensão de conhecimentos sobre os direitos humanos; a afirmação de valores, atitudes e práticas que expressem uma cultura de direitos humanos; a afirmação de uma consciência cidadã, o desenvolvimento de processos metodológicos participativos, e o fortalecimento de práticas individuais e sociais que gerem ações e instrumentos em favor da promoção, da proteção e defesa dos direitos humanos.

Em acordo com o Programa Mundial de Educação em Direitos Humanos da ONU, a política pública de educação em direitos humanos considera que os direitos humanos são uma área de conhecimento transdisciplinar que deve estar presente na formação de todas e todos desde a mais tenra idade, alcançando, inclusive, a formação inicial e continuada de nível superior de todos os cursos.

A certeza de que há muito ainda a ser conquistado no campo do respeito à dignidade da pessoa humana nos impele a aprofundar cada vez mais os processos formativos inspirados nos valores humanistas embasados nos princípios da igualdade, da diversidade, da solidariedade e da fraternidade entre os seres humanos. A afirmação da universalidade, da indivisibilidade e da interdependência desses direitos fundamentais constitui o lastro para implantação na sociedade de uma cultura de direitos humanos, de respeito às diversidades e de formação de cidadãos capazes de zelar pelo exercício e pelo controle democrático das ações do Estado.

Os fundamentos teóricos e metodológicos para a educação em direitos humanos estão presentes numa abordagem teórico crítica da educação, considerando que seus objetivos adotam uma visão crítica e transformadora dos valores e atitudes, relações e práticas sociais.

A educação em direitos humanos é essencialmente a formação de uma cultura de respeito À dignidade humana através da promoção e da vivência dos valores da liberdade, da justiça, da igualdade, da solidariedade, da cooperação, da tolerância e da paz. Portanto, a formação desta cultura significa criar, influenciar, compartilhar e consolidar mentalidades, costumes, atitudes, hábitos e comportamentos que decorrem, todos, daqueles valores essenciais citados - os quais devem se transformar em praticas (BENEVIDES,2003). 


\section{autêntica}

Para entendermos a necessidade da educação em direitos humanos basta olharmos na realidade atual brasileira, quando olhamos para este cenário percebemos que apesar de termos uma Constituição cidadã, leis progressistas e instituições democráticas, ainda vivenciamos uma realidade educacional e social que insiste em sonegar direitos, principalmente, das pessoas em situação de vulnerabilidade social, e manter práticas discriminatórias e graves violações, produzidas e reproduzidas por culturas e preconceitos institucionais, mentalidades e atitudes que desrespeitam os direitos humanos.

Essa concepção de direitos humanos incorpora a compreensão de cidadania democrática, cidadania ativa e cidadania planetária, embasadas nos princípios da liberdade, da igualdade, da diversidade, e na universalidade, indivisibilidade e interdependência dos direitos. A democracia, ao ser entendida como regime alicerçado na soberania popular e no respeito integral aos direitos humanos, é fundamental para o reconhecimento, a ampliação e a concretização dos direitos.

Nesse entendimento, o processo de construção da cidadania ativa requer, necessariamente, a formação de cidadãos conscientes dos seus direitos e deveres, e protagonistas da materialidade das normas e pactos que os regulamentam, englobando a solidariedade internacional e o compromisso com outros povos e nações.

A educação é tanto um direito em si mesmo, como um meio indispensável para realizar outros direitos, constituindo-se como um processo amplo que ocorre na sociedade e ganhar maior importância quando direcionada ao pleno desenvolvimento humano e às suas potencialidades e a elevação da autoestima dos grupos socialmente excluídos, de modo a efetivar a cidadania plena para a construção de conhecimentos, no desenvolvimento de valores, crenças e atitudes em favor dos direitos humanos e da justiça social.

Com base nesses pressupostos, temos oferecido a comunidade uma série de atividades de informação, especialmente, a professores da rede pública e universitários. Destacamos o Seminário Metodologias Participativas e Estudos Sobre Comunidades que já está em sua terceira edição. Sendo a pesquisa em educação em direitos humanos uma pesquisa essencialmente participativa, neste seminário buscamos produzir e difundir conhecimento sobre essas metodologias.

\subsection{ABORDAGEM BASEADA EM DIREITOS HUMANOS (RBA)}

Em nossas atividades utilizamos uma metodologia conhecida como Abordagem Baseada em Direitos humanos (Human Right-Based Aprooaches) que parte do princípio de que a não prestação de serviços públicos essenciais pelo Estado, em última análise, é uma violação a direitos humanos. A RBA está fundamentada na estrutura normativa dos direitos humanos e em intervenções diretas visando desenvolver a capacidade dos detentores de direito de reivindicar seus direitos e a habilidade dos encarregados (agentes públicos) em cumprir suas obrigações. Em outras palavras, a abordagem baseada em direitos pretende contribuir para que a população de forma cívica e cidadã passa a reivindicar seus direitos previstos na legislação nacional e internacional e a participar do espaço público de decisão.

Abordagens Baseadas em Direitos ou em inglês Right Based Approaches (RBA) é uma metodologia recomendada pela Organização das Nações Unidas (ONU) e utilizada por agências multilaterais e ONGs, para projetos e programas que trabalham com o direito ao desenvolvimento, especialmente, em setores como educação, saúde, governança, água, nutrição, saneamento básico, HIV/AIDS, emprego, relações de trabalho, relações sociais, desenvolvimento econômico sustentável entre outros. 


\section{autêntica}

Normalmente as referências a essa metodologia são encontradas na rede mundial de computadores de diversas formas. As mais comuns são: no singular "Abordagem Baseada em Direitos" (Right-Based Approach); no plural "Abordagens Baseadas em Direitos" (Right-Based Approaches); ou com referência aos direitos humanos "Abordagens Baseadas em Direitos Humanos" (Human Right-based Approaches). É comum também a expressão "Abordagem Baseada nos Direito para o Desenvolvimento" ou (Right-Based Approach to Development).

Os usuários dessa metodologia concordam, no entanto, que não existe uma única forma de utilização dessa metodologia, cada grupo, considerando sua situação particular, constrói seu método com base nos princípios e procedimentos comuns da RBA. Nesse aspecto, concordamos que não existe uma única abordagem baseada em direito, mas uma diversidade de formas de abordagens baseadas em direitos que se aplicam as diversas áreas do conhecimento. Em nosso caso, utilizamos a expressão "Abordagens Baseadas em Direitos" no plural ou a sigla RBA respeitando a ideia de pluralidade de iniciativas.

Os Direitos Humanos são considerados pela RBA como universais, inalienáveis, indivisíveis, imprescritíveis, interdependentes e inter-relacionados e devido a todas as pessoas independente de raça, cor, sexo ou condição social. Como o seu foco, contudo, está nas pessoas e grupos que são mais vulneráveis, excluídas ou discriminadas, o enfoque de gênero, etnia e classe social também está na base dessa metodologia.

Essa definição de direitos humanos considera-os como um múltiplo conjunto indivisível, interdependente e inter-relacionado de direitos civis, políticos, econômicos, social, culturais e ambientais. Isto implica que o sistema internacional de direitos humanos garante, por exemplo, direitos como a saúde, educação, moradia, acesso à justiça, segurança pessoal e participação política (ROMANO e ANTUNES, 2002, p.36).

A RBA tem como referência a noção de desenvolvimento humano, normativamente orientados pelos princípios de Direitos Humanos presentes nas declarações, pactos, convenções e tratados internacionais, a exemplo da Carta Internacional dos Direitos Humanos que é constituída pela Declaração Universal dos Direitos Humanos (DUDH), pelo Pacto Internacional sobre os Direitos Econômicos Sociais e Culturais (PIDHESC) e pelo Pacto Internacional sobre os Direitos Civis e Políticos e seu protocolo facultativo. Outros documentos importantes para a RBA são: a Declaração sobre Direito ao Desenvolvimento (1986); a Declaração de Direitos Humanos e Programa de Ação de Viena (1993); e da Declaração e Objetivos Internacionais do Milênio da ONU.

O conjunto desses documentos internacionalmente aceitos, que protegem os direitos humanos, fornece padrões reconhecidos globalmente do que significa viver com dignidade, mostrando-se também, como sistema jurídico de considerável força e legitimidade social no plano internacional e nacional, desde o fim da segunda guerra mundial. Segundo Romano e Antunes (2002, p.35).

\footnotetext{
"A abordagem com base em direitos para o desenvolvimento é uma estrutura conceitual que assenta em padrões e operacionalização voltadas para a promoção e proteção dos direitos humanos. Ela integra as normas, padrões e princípios do sistema internacional de direitos humanos em planos, políticas e processos de desenvolvimento. As normas e standards são aqueles contidos no rico acervo de tratados e declarações internacionais. Os princípios incluem: igualdade, equidade, prestação de contas, empoderamento e participação. "
}

A RBA é também uma estratégia para efetivar o direito humano ao desenvolvimento (Right-Based Approach to Development). Essa estratégia apaga as distinções entre direitos ao desenvolvimento e direitos humanos 


\section{autêntica}

e tem como objetivo reduzir a dependência das comunidades de ajuda externa e melhorar a capacidade dos governos de atender as necessidades da população. Com essa estratégia afirmamos que na base das abordagens baseadas em direito está não só o trabalho de defesa e promoção dos direitos humanos da população, mas a construção de políticas públicas e ações afirmativas junto ao Estado.

Essa perspectiva coloca a cidadania e os direitos humanos não só como "o direito a ter direitos" (cidadania negativa), mas "o direito a construir novos direitos" (cidadania positiva). Nesse aspecto, a comunidade deve ser preparada a não só conhecer quais são os seus direitos, mas como eles podem ser exigidos junto ao Estado. Deste modo, a RBA é uma estratégia utilizada por Agências Multilaterais, ONGs, Institutos de Pesquisa e Universidades para efetivar o direito humano ao desenvolvimento sustentável, mas, também, para desenvolver projetos de pesquisa aplicada e extensão em direitos humanos ou que tragam em seu bojo preocupações com a cidadania.

\subsection{INDISSOCIABILIDADE ENTRE ENSINO, PESQUISA E EXTENSÃO COM FOCO NA INOVAÇÃO}

A experiência que o OBEDHUC vem desenvolvendo com a formação de professores tem se mostrada capaz de construir redes de educação cidadã como se propõe, demonstrando ser materializável a preocupação manifesta no Plano Nacional de Educação em direitos humanos de que os direitos humanos sejam um eixo norteador da formação de professores, tornando a educação em direitos humanos um campo específico para o ensino, a pesquisa e a extensão universitária. Mais que simplesmente adotar essa perspectiva como uma dimensão articuladora, ousou em fazer dos direitos humanos um eixo norteador das atividades curriculares e de pesquisa, extensão e ensino, demonstrando a vocação natural da extensão universitária como articuladora da indissociabilidade entre ensino e pesquisa.

Nosso recorte epistemológico e metodológico relacionado à pesquisa sempre esteve focado no desenvolvimento de métodos participativas de pesquisa, questão ética fundamental para pesquisadores em direitos humanos. Com isso nossa opção foi por métodos como a pesquisa-ação colaborativa onde os participantes são mais do que sujeitos ativos, são coprodutores do conhecimento. Nessa perspectiva desenvolvemos já duas edições do seminário Metodologias Participativas e Extensão em Comunidade, espaço de livre circulação de ideias com o objetivo de aprofundar as questões de pesquisa em relação métodos participativos sem perder o rigor científico. Maiores informações podem ser obtidas no site do evento: http://participativas. blogspot.com.

Nosso Observatório está vinculado a Programas de Pós-Graduação Stricto Sensu de características diferentes, estamos vinculados a um doutorado acadêmico e a um mestrado profissional. Com isso, foi uma característica de nosso trabalho a pesquisa em direitos humanos e uso de metodologias de pesquisa aplicada.

Para nossa equipe, a extensão universitária é mais do que uma função da universidade, ela é o lócus privilegiado da relação com a comunidade, ela é uma forma de se fazer a pesquisa e o ensino de forma participativa. Com isso, o Observatório desenvolveu diversas atividades consideradas como extensionista com o fim especial de promover o ensino e a pesquisa em articulação com a sociedade.

Vale destacar que a extensão permite o contato com um ambiente social fundamental na formação profissional e humana do pesquisador, não se aprende a pesquisa em direitos humanos apenas lendo um livro, não se aprende apenas pela cognição, a emoção, as experiências são fundamentais nesse processo. É a extensão, portanto, que possibilita o campo para a pesquisa no Observatório. 


\section{autêntica}

Ensinar pela pesquisa-extensão é o princípio educativo do ensino superior. Em relação a pós-graduação stricto sensu o Observatório vem contribuindo diretamente com o tópico especial Políticas Públicas, Educação e Direitos Humanos, com carga horária de 45h, no Mestrado Profissional em Gestão e Tecnologia Aplicada à Educação (GESTEC). Em relação a pós-graduação lato sensu o Observatório coordenou o curso de especialização em Gestão em Direitos Humanos, parceria da Universidade do Estado da Bahia (UNEB) com a Secretaria de Justiça, Direitos Humanos e Cidadania (SJCDH/BA), atualmente, Secretaria de Justiça, Direitos Humanos e Desenvolvimento Social (SJDHDS).

Na graduação, o Observatório realizou também atividades de ensino nos cursos de pedagogia, direito, ciências contábeis entre outros. Através da iniciação científica estudantes bolsistas puderam ter bolsas do CNPq, da Fundação de Amparo à Pesquisa no Estado da Bahia (FAPESB) e da própria UNEB para desenvolver seus trabalhos de pesquisa. Contribuiu ainda com projetos especiais da UNEB, UFBA e UCSAL, assim como com a integração da Educação em Direitos Humanos nos cursos de graduação das respectivas universidades, como orienta a Resolução n 01 de 2012 do Conselho Nacional de Educação (CNE) que institui as Diretrizes Nacionais da Educação em Direitos Humanos.

\subsection{A INTERDISCIPLINARIDADE}

A proposição de atividades interdisciplinares tem sido a tônica do projeto, a educação em direitos humanos já é concebida pelo plano como uma área transdisciplinar, nesse sentido, o OBEDHUC é o espaço para abordagem de problemas educacionais de maneira interdisciplinar envolvendo pesquisadores de diferentes áreas do conhecimento na resolução de um problema em comum.

\subsection{COGNIÇÃO X EMOÇÃO}

O estudo de livros, artigos científicos e textos sobre direitos humanos, assim como a participação em atividades de formação são importantes, mas a realização de vivências em comunidade é fundamental para a formação humana do professor. Costumamos dizer que o ser humano não se forma somente pela cognição, ele precisa das emoções, da vivência com a comunidades, com o contato direito com a realidade para entender o problema e tentar solucioná-lo.

\section{CONCLUSÃO}

Em síntese, podemos concluir pela importância da implantação do projeto do Observatório da Educação em Direitos Humanos (OBEDHUC) em nossa universidade. Passada as dificuldades iniciais como local para funcionamento do projeto, formação da equipe, desenvolvimento de ferramentas como o Portal Mbote, a compreensão por parte de todos quais eram os objetivos do laboratório e institucionalização da proposta, o projeto se apresenta com altamente produtivo em termos gerais favorecendo a produção de conhecimento em suas instalações e sendo responsável pela difusão desse conhecimento através de seminário, minicursos e atividades e formação.

O OBEDHUC qualificou a ação de pesquisa, sendo registrado como laboratório de pesquisa na Plataforma Sucupira, favoreceu ao surgimento de outros Observatórios na instituição e, recentemente, teve seu valor reconhecido pela comunidade universitária quando o CONSU através da Resolução 1247/2016 criou o Centro de Referência em Desenvolvimento e Humanidades (CRDH/UNEB) que de agora em diante dará vida e sustentação ao Observatório e outros projetos de pesquisa. 


\section{autêntica}

Em relação à institucionalização, podemos concluir que a estratégia de organizar o OBEDHUC enquanto laboratório de pesquisa aplicada em ciências humanas, sociais e sociais aplicadas, favoreceu o reconhecimento institucional do projeto, a agregação de pesquisadores e captação de recursos para o desenvolvimento de ações. Também estimulou a formação de uma cultura de uso de laboratórios nos cursos de ciências humanas, sociais e sociais aplicadas. A integração se completa com a vinculação ao $\mathrm{CRDH} / \mathrm{UNEB}$ e aos programas de pós-graduação da universidade, favorece também ao oferecimento de cursos atividades complementares para os cursos de graduação e pós-graduação, bem como ao desenvolvimento de projetos de pesquisa extensão.

Em relação à produção, basta uma olhada nos números conquistados para ver a importância desse equipamento, mais de uma centena de trabalhos publicados e/ou apresentados em eventos demonstram que a estratégia de formação de redes e produção coletiva do conhecimento, de forma inter e transdisciplinar, é a melhor forma de gestão do conhecimento nos dias atuais.

Por fim, não poderíamos deixar de destacar o papel do OBEDHUC na socialização dos princípios e diretrizes da política nacional de educação em direitos humanos, como a lei não se autoaplica, é fundamental desenvolver ações para efetivação dessa política pública e o OBEDHUC foi um instrumento para isso, é importante destacar o papel do Observatório em sua formação profissional e humana.

Esperamos que o relato dessa experiência estimule a outros grupos a construírem seus laboratórios de pesquisa e fomentem a produção e difusão de conhecimento necessário ao desenvolvimento de nosso Brasil enquanto uma nação democrática.

A institucionalização do OBEDHUC enquanto Laboratório de pesquisa aplicada em ciências humanas, sociais e sociais aplicadas é considerado hoje pela Universidade como o formato adequado para projetos dessa natureza facilitando a alocação de recursos materiais e humanos.

Em verdade, foi o projeto do OBEDHUC que possibilitou a formação dos outros laboratórios de pesquisa que permitiram em 2016 a criação do Centro de Referência em Desenvolvimento e Humanidades (CRDH) através da Resolução 1247/2016 do CONSU/UNEB. Enquanto órgão suplementar da universidade a criação do $\mathrm{CRDH} / U N E B$ dá autonomia administrativa e financeira ao projeto garantindo que o OBEDHUC continue a ser um espaço de produção e difusão do conhecimento e articulação da rede de pesquisa dos profissionais da educação.

Atualmente o CRDH/UNEB congrega mais de 50 (cinquenta) pessoas que estão ou fazendo seus projetos de pesquisa, ou amadurecendo suas propostas para a submissão. Essas pessoas assinam com o centro um termo de trabalho voluntário e participam de todos os projetos do centro de pesquisa como a organização de atividades de formação e pesquisa. Isso tem atraído muitas pessoas pelo trabalho e as perspectivas para 2017 é o crescimento do projeto com novas ações. Para 2017 a principal ação será a proposição de um mestrado profissional com apoio da Fundação de Amparo à Pesquisa do Estado da Bahia (FAPESB). 


\section{REFERÊNCIAS}

BOESEN, Jakob Lirkemann e MARTN, Thomas. Applying a rights-based approach: an inspirational guide for civil society. The Danish Institute e for Human Rights. Copenhagem, Dinamark, 2007.

BRASIL. Plano Nacional de Educação em Direitos Humanos (PNEDH). Disponível em http://www.sdh.gov. br. Acesso em 15.09.2016.

BRASIL. Programa Nacional de Direitos Humanos (PNDH), versões I, II e III. Disponível em http://www.sdh. gov.br. Acesso em 15.09.2016.

BRASIL. Resolução nº 01 que institui as Diretrizes Nacionais da Educação em Direitos Humanos. CNE: Brasília. 2012.

PINO, Angel. Violência, Educação e Sociedade: Um Olhar sobre o Brasil Contemporâneo. Revista Educação e Sociedade. vol.28 no.100 Campinas Oct. 2007.

ROCHA, José Cláudio. A Reinvenção Solidária e Participativa da Universidade. EDUNEB, Salvador, Bahia, 2008.

ROCHA, José Cláudio. Guia de Educação em Direitos Humanos, UNEB, Camaçari, 2009.

ROCHA, José Cláudio. Metodologia da Pesquisa Para a graduação e pós-graduação presenciais e EAD: uma introdução à abordagem baseada em direitos. Editora Appris, Curitiba, 2012.

ROCHA, José Cláudio e ROCHA, Denise A.B.F. Metodologia para a Extensão em Educação em Direitos Humanos: Programa de Extensão Educação Jurídica Popular em Direitos Humanos - Construindo Redes de Educação Cidadã, Camaçari, UNEB, 2009.

ROMANO, Jorge e ANTUNES, Marta. Empoderamento e direitos no combate à pobreza. Rio de janeiro, ActionAid Brasil, 2002. 
